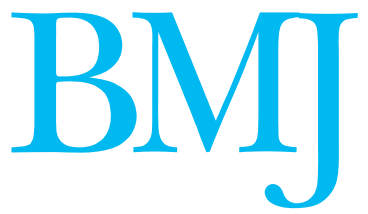

\title{
Personal knowledge
}

\author{
Doctors are much more than simple conduits for clinical evidence
}

C houdry and colleagues' paper in this issue (p 141) is a brave attempt to quantify the under-recognised notion of personal knowledge in clinical practice. ${ }^{12}$ They carefully analysed the prescribing decisions of hospital doctors caring for patients with atrial fibrillation, before and after their exposure to a patient with an adverse event-either serious haemorrhage when taking warfarin, or a thromboembolic event while not taking warfarin. The researchers wanted to know whether doctors' knowledge of a previous adverse event affected their subsequent prescribing.

For the group of doctors who were exposed to patients with adverse bleeding events, and who cared for atrial fibrillation patients subsequently, the odds that they would prescribe warfarin were $21 \%$ lower for subsequent patients. There was no statistically significant change in warfarin prescribing after a doctor cared for a patient who had had a stroke while not taking warfarin, nor-in support of the specificity of the study's findings-was there any change in prescribing of angiotensin converting enzyme inhibitors by doctors with exposure to patients who had either bleeding events or strokes. Doctors' experiences of bleeding events associated with warfarin can influence warfarin use, the team concluded, and adverse events associated with the underuse of warfarin may not affect subsequent prescribing.

Doctors are neither passive recipients of, nor simple conduits for, clinical evidence. ${ }^{3}$ We conduct an "inner consultation" with evidence, analysing it in both a logical and intuitive way. ${ }^{4}$ In so doing, we are exposed to what Tvensky and Kahneman call the "availability heuristic"- a fancy way of saying that we are more likely to recall events which are more easily recalled-and the "chagrin factor," whereby doctors tend to avoid actions that cause them hassle. ${ }^{5}$ Patients conduct similar internal conversations, adding the experience of a consultation to their previous intellectual and emotional understanding of illness.

Currently two compass points guide these consultations: statistical significance and clinical significance. While necessary, these are not enough to clarify the dynamic interaction between a patient and a doctor. A third dimension is personal significance, a concept that captures the reciprocity of the evaluation and interpretation of a new idea by a doctor and patient together. ${ }^{7}$

All of us, including doctors, have our own "view perspectives on what they choose to look at, but are rather more able to reconcile particularities, through the conventions of intersubjective agreement, to create what they call "an objective account." This has the air, however, of a "view from nowhere." At stake here is something quite profound, and poorly accepted within the medical community: the personal participation of the knower in all acts of understanding. This is the central thesis of Polanyi's great work, echoed in the title to this editorial. ${ }^{1}$ The philosopher Polanyi, a professor of physical chemistry and then of social studies, argues that comprehension is neither an arbitrary nor passive act and requires tacit skills of judgment. These skills are neither algorithmic nor exhaustively specifiable, but underpin the connection between passion and knowing.

Intellectual passions have an affirmative content. In science, they help us decide what to explore, selecting some options over others. Heuristic passions help us discover things, urging us at times not to accept at face value what is given or conventionally accepted. And persuasive passion turns both of those into controversial debate, by which scientific communities define themselves. In medical consultations there are two participants, both personally knowing, both passionately participating, but from different perspectives, different "somewheres." The outcome of their interaction, in the form of the clinical decision, is an emergent property of two ways of knowing: biomedical and biographical. This forces doctors to confront an intersection of the two epistemologies and to ask questions about their respective legitimacy (is one inherently superior?) and inter-relationship (on which occasions should one dominate?).

Chaudry and colleagues' paper illuminates this murky area for us and provides convincing evidence that, within each doctor, these two ways of knowing compete for influence. When the authors remark, at the end of their paper, that "one would hope that providers who prescribe more frequently, and who are specialists, would be least likely to be influenced by experiences with individual patients" one senses how much we all have to learn about personal knowing.

Kieran Sweeney honorary clinical senior lecturer in general practice

(kieran.sweeney@pms.ac.uk)

Peninsula Medical School, Exeter EX2 5DW

Competing interests: None declared. 
1 Polkinghorne J. Science faith and understanding. New York: Yale University Press, 2001.

Nagel T. The view from nowhere. Oxford: Oxford University Press, 1986

Choudry NK, Anderson GM, Laupacis A, Ross-Degnan D, Normand ST, Soumerai SB. Impact of adverse events on prescribing warfarin in patients with atrial fibrillation: matched pair analysis BMJ 2006;332: $141-3$.

4 Polanyi M. Personal knowledge: towards a post critical philosophy. Chicago: University of Chicago Press, 1958.
5 Freeman A, Sweeney K. Why general practitioners do not implement evidence: a qualitative study $B M J$ 2001:323:1100-4.

Neighbour R. The inner consultation. Lancaster: MTP Press, 1987

7 Tversky A, Kahneman D. Judgment under uncertainty: heuristics and biases. Science 1974;185:1124-31.

8 Feinstein AR. The chagrin factor and qualitative decision analysis. Arch Intern Med 1985;145:1257-9.

9 Sweeney KG, MacAuley D, Pereira Gray DJ. Personal significance: the third dimension. Lancet 1998; 351:134-6.

\title{
Using personal health information in medical research
}

\author{
Overzealous interpretation of UK laws is stifling epidemiological research
}

$\mathrm{R}$ ecent growth in the regulation of research involving patients or their personal data in the United Kingdom-such as research governance, the European clinical trials directive, the Data Protection Act 1998, the Human Tissue Act 2004, the Mental Capacity Act 2005, and guidance from the General Medical Council-has caused delays, higher costs, and sometimes cessation of research projects. ${ }^{12}$ Rules around privacy, confidentiality, and consent have become particularly complex and confusing.

The people appointed to protect personal health data sometimes seem to feel no need to facilitate research. These include Caldicott guardians (board members and senior health professionals appointed by each health authority, NHS trust, and primary care group to safeguard the confidentiality of patient information) and data protection officers who often work with medical records departments. These guardians and officers and their organisations are averse to risk and often restrict or deny access to personal medical data, interpreting the Data Protection Act as insisting that patients must consent directly to participate in research or that patients' data must be completely anonymised.

This causes particular problems for epidemiological research, ${ }^{3}$ which often requires access to routinely collected identifiable personal data, or requires identification of research participants from such data. Obtaining individual consent from large numbers of patients may be onerous or simply impossible, for example if patients have died or moved away, and participation bias may undermine the data. Anonymising data is difficult and expensive and greatly limits their future value.

The information commissioner-an independent official appointed by the Crown to oversee the Data Protection Act 1998, the Freedom of Information Act 2000, and the Environmental Information Regulations 2004-takes a more liberal view. The commissioner has decided that, while obtaining consent for medical research involving identifiable personal health data is the default position, consent is not required where such access to the data is necessary (for example in a research protocol approved by an ethics committee), is considered proportionate and no more with respect to privacy and public interest, and where there is "fair processing" (meaning that the patient should be informed of the data collection and have the right to opt out). ${ }^{4}$ Even informing the patient may be waived if the effort to do so is disproportionate, especially if the research is "historical or statistical." Transparency and proportionality are also emphasised in the NHS research governance framework. ${ }^{5}$ Many data controllers responsible for the implementation of the Data Protection Act seem unaware that there are reasonable exceptions to the general rule of consent.

The risks to the individual patient from epidemiological research, subject to high standards of data handling and preservation of confidentiality, are minimal when compared with the risks in interventional research. ${ }^{6}$ The potential benefits to the public are great but many people have misinterpreted the regulations to imply that both types of research have similar standards for informing patients and obtaining consent. But proportionality of risk is a judgment, not an absolute, and needs to be considered impartially by an appropriate body independent of the researchers, probably an ethics committee in most cases.

These issues are considered comprehensively in an excellent new report from the UK Academy of Medical Sciences, which argues strongly for a clearer framework for using personal health data in research. ${ }^{7}$ Furthermore, a paper in this issue by Iversen and colleagues ( $p$ 165) supports the arguments of the academy, and might almost have been written to illustrate the worst excess of over-regulation identified by the academy, specifically misinterpretation of the Data Protection Act. ${ }^{8}$ The contentious issue is less the law than its overly conservative interpretation-although if the Office for National Statistics can't get it right, who can?

One study suggests, however, that the public do not uncritically support free access to their records by medical researchers, though the participants in this work seemed to have only limited understanding of the purposes and conduct of medical research. ${ }^{9}$ The academy reports consultations with well informed patient groups which have more palatable findings for researchers. ${ }^{7}$ And Iversen suggests that poor response rates in research are related more to patients' apathy rather than antipathy. ${ }^{8}$ Both reports argue for greater engagement of the public and more empirical research on these issues.

Are there legal risks for researchers? No researchers in the United Kingdom have been prosecuted for misusing data in properly conducted and approved research, but there is no case law to support the use of data in this way. The General Medical Council's advice, however, seems to lack any consideration of proportionality, and goes beyond the Data Protection Act in requiring express consent for the use of personal data in research (but not in disease registries-a fine
Analysis and comment p 165

BMJ 2006;332:130-1 